\begin{tabular}{l} 
Sharif University of Technology \\
Scientia Iranica \\
SCIENTIA \\
IRAN \\
Thansactions A: Civil Engineering \\
\hline
\end{tabular}

\title{
Effect of cement grain size on the geotechnical properties of stabilized clay
}

\author{
M. Mollamahmutoglua and E. Avci ${ }^{\mathrm{b}, *}$ \\ a. Department of Civil Engineering, Gazi University, Yükseliş Street. No: 5 Maltepe Ankara, Turkey. \\ b. Department of Civil Engineering, Bursa Technical University, 152 Evler Street No: 2/10, Yıldırım-Bursa, Turkey. \\ Received 21 September 2017; received in revised form 27 November 2017; accepted 1 January 2018
}

\section{KEYWORDS \\ Clay stabilization; Cement type; \\ Strength; \\ Permeability; \\ Compressibility; \\ Swelling.}

\begin{abstract}
In this study, some geotechnical properties of Microfine Portland Cement (MPC) and Portland Cement (PC) stabilized High Plasticity Clayey Soil (HPCS) samples were investigated. The results showed that liquid limit, permeability, swelling potential, and compressibility of HPCS were reduced, and HPCS's plastic limit and Unconfined Compressive Strength (UCS) were increased by both MPC and PC stabilizations. Besides, liquid limit, permeability, swelling potential, and compressibility of HPCS were further reduced by MPC. Although dry UCS of MPC stabilized HPCS sample was almost the same as that of PC stabilized HPCS sample, the plastic limit and wet cured UCS of MPC stabilized HPCS sample were higher than those of wet cured UCS of PC stabilized HPCS sample. In general, as the size of cement particles becomes finer, the stabilization of HPCS becomes more effective.
\end{abstract}

(C) 2019 Sharif University of Technology. All rights reserved.

\section{Introduction}

High plasticity clayey soil exists in many parts of the world. Their important properties include high plasticity, low strength, high swelling, and shrinkage potential. These soil properties often bring about bearing capacity problems in structural foundations, underground facilities, highways, and airfield pavements [1]. The annual cost of the damage of expansive soils to structures, such as buildings, buried utility, and roads, was estimated at $£ 150$ million in the UK, $\$ 1000$ million in the U.S., and many billions of pounds worldwide [2]. To tackle these issues, there are many methods for treating the soils under study. Existing

\footnotetext{
*. Corresponding author. Tel.: +905074656336, $+902243003741$

E-mail addresses: mmolla@gazi.edu.tr ( $M$.

Mollamahmutoglu); eyubhanavci@gmail.com (E. Avci)
}

methods are categorized as mechanical and chemical stabilizations, in general. Lime, cement, and fly ash are the main additives used in chemical stabilization [3-6]. They produce a chemical reaction that takes place in a soil water system, which stabilizes the soil in the long run.

Stabilization of soils with cement is the oldest, well-known method worldwide. The stabilization of clayey soils through the addition of cement involves four different chemical processes: cation exchange, flocculation and agglomeration, cementitious hydration, and pozzolanic reaction [7]. When the pore water of clayey soil is exposed to cement, hydration reaction of cement occurs, which is relatively fast and results in an immediate strength gain in the soil. In addition, the cation exchange and the flocculation-agglomeration process occur immediately after mixing the clayey soil and cement, causing a reduction in clayey soil plasticity. The lime generated during hydration of the cement helps increase the binding between soil particles through the pozzolanic reactions. The cement 
hydration and pozzolanic reaction may last for months or even years after mixing; thus, the strength of cement treated clayey soil is expected to increase with time [8].

Such factors as soil type and its characteristics (Atterberg limits, grain size distribution of soil, and organic soil content), type and amount of cement (slag cement or Portland cement), mixing and compaction methods, curing environment, and time regarding the stabilized clayey soils have been studied by many authors. The strength of cement-stabilized clayey soil was dependent on the chemical components of cementing agents [9-11], and it increased with the increase of cement content $[12,13]$. It was reported that the finer the grain size range of soil was, the higher the compressive strength was $[14,15]$. It was also found that the strength of cement-stabilized clayey soil increased with the increase of curing time [1618]. Achieving a good mixture of stabilizers was the most important factor that affected the quality of results [19]. It was stated that organic matter could negatively affect the efficiency of cement-stabilized clayey soil [20]. The effective cohesion intercept and internal friction angle for high plasticity clayey soil increased with the increase of cement content and curing time [13,21]. As the clay content increased, a higher quantity of cement agents was necessary to increase the strength [22]. The plastic limit of cementstabilized clayey soil increased with the increase of cement content and curing time $[13,19,23,24]$. The resistance of clayey soil to compression was markedly enhanced by cement stabilization $[25,26]$. The permeability of cement-stabilized clayey soil was reduced with an increase in cement content and curing time [24,27]. The addition of cement to expansive clayey soil reduced its swelling potential [1,28].

Nevertheless, the effect of cement particle size on the cement-stabilized clayey soil, especially on expansive clayey soil, has not been taken into consideration so far. Therefore, the aim of this study is mainly to focus on the influence of cement fineness on such geotechnical properties as unconfined compressive strength, permeability, swelling, and compressibility of cement-stabilized high plasticity clayey soil taking into account curing time and conditions.

\section{Materials used}

\subsection{Clayey soil}

The clayey soil used in this research was collected from Golbası region, Ankara, Turkey. A nearly $0.5 \mathrm{~m}$ thick layer of organic soil was clearly removed, and disturbed samples were taken by backhoe from a depth of about $1.5 \mathrm{~m}$. The blocky soil samples were transported to the Geotechnical Laboratory of Gazi University and divided into small pieces, spread over the floor, dried out in the open air at room temperature, and then

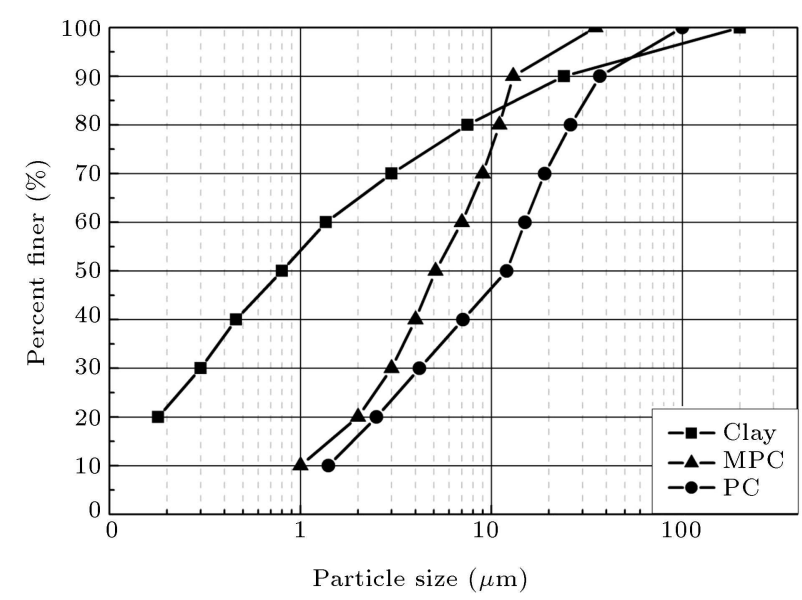

Figure 1. Grain size distribution of clayey soil, PC, and MPC.

finely pulverized into powder using a rubber hammer. In addition, the grain size distribution (Figure 1), Atterberg limits, specific gravity, and organic content were determined (Table 1) with reference to ASTM D 422-63, ASTM D 4318-10e1, and ASTM D 854-02, respectively [29-31]. The clayey soil was then classified as high plasticity clay $(\mathrm{CH})$ according to Unified Soil Classification System (USCS) [32].

\subsection{Portland and microfine Portland cements}

The cement cases used in this study include Type I of PC and Rheocem 650 as MPC [33]. Rheocem 650 is a well-graded cement milled from pure Portland cement clinker. The particle size distributions of both types of cement were obtained from laser particle size analyzer, as given in Figure 1. As observed, the particle sizes of Rheocem 650 were much smaller than those of PC. Moreover, some physical and chemical properties of cement are summarized in Table 2. Moreover, MPC is produced in some European countries, USA, and Japan; therefore, its production cost is about 3 times that of PC.

Table 1. Some properties of soil.

\begin{tabular}{lc}
\hline Basic characteristics and description & Values \\
\hline Specific gravity & 2.80 \\
Passing no. 200 sieve (<0.075 mm) (\%) & 98.6 \\
Plastic limit (\%) & 29 \\
Liquid limit (\%) & 104 \\
Plasticity index (\%) & 75 \\
Free swell (uncompacted sample) (\%) & 17.7 \\
Soil class (USCS) & $\mathrm{CH}$ \\
Organic material (\%) & 2.29 \\
\hline
\end{tabular}


Table 2. Physico-chemical properties of PC and MPC.

\begin{tabular}{ccc}
\hline Properties & PC & MPC \\
\hline $\mathrm{SiO}_{2}$ & 18.8 & 19.8 \\
$\mathrm{Al}_{2} \mathrm{O}_{3}$ & 4.0 & 4.2 \\
$\mathrm{Fe}_{2} \mathrm{O}_{3}$ & 5.3 & 4.1 \\
$\mathrm{CaO}$ & 62.2 & 62.5 \\
$\mathrm{MgO}$ & 2.0 & 2.8 \\
$\mathrm{SO}_{3}$ & 3.25 & 2.1 \\
$D_{50}(\mu \mathrm{m})$ & 12 & 5.1 \\
$D_{95}(\mu \mathrm{m})$ & 60 & 11.2 \\
Specific gravity & 3.19 & 3.10 \\
Fineness $\left(\mathrm{cm}^{2} / \mathrm{g}\right)$ & 3.836 & 6.250 \\
\hline
\end{tabular}

\section{Testing program}

\subsection{Preparation of $P C$ and $M P C$ clayey soil specimens}

Initially, clayey soil and cement contents were dried in an oven at $105^{\circ} \mathrm{C}$ overnight. Thereafter, the ovendried specimens were mechanically mixed in a dry condition. The mixtures of both PC and MPC modified specimens were based on dry weight percentage rates of PC and MPC in the clayey soil matrix. To perform this experimental study, PC and MPC contents were selected as $8 \%, 10 \%$, and $12 \%$.

\subsection{Determination of Consistency limits}

The consistency limits for cement treated and untreated clayey soil samples were determined in accordance with ASTM D4318-10e1 standard [30]. Figure 2

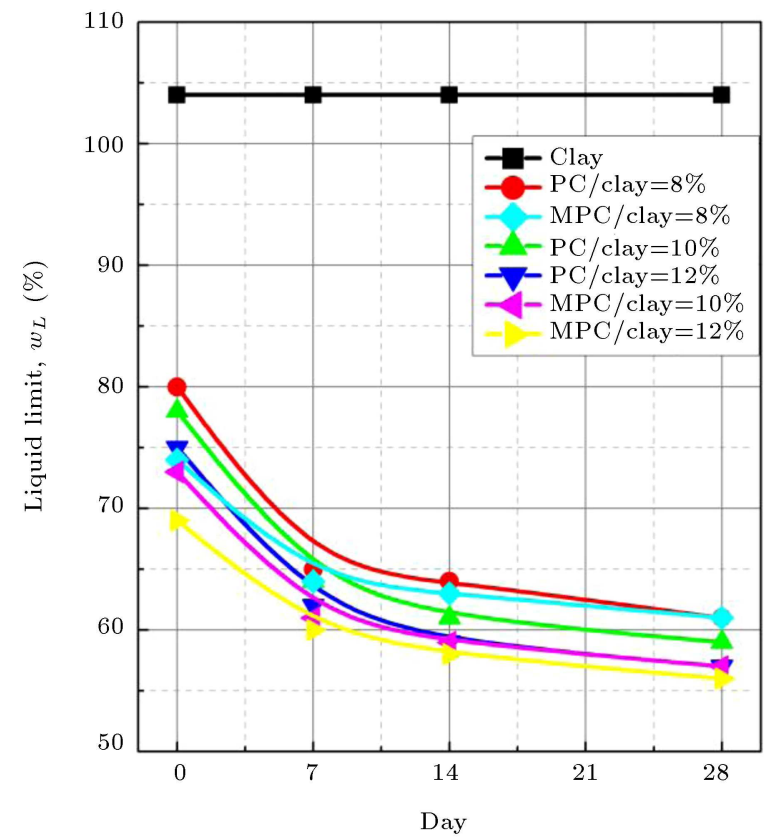

shows the results of the consistency limit tests on untreated, PC, and MPC treated clayey soil samples.

\subsection{Determination of compaction properties}

Maximum dry unit weights of PC and MPC amended clayey soil samples were determined by a standard laboratory compaction test [34]. The compaction test results are shown in Figure 3.

\subsection{Preparation of PC and MPC amended clayey soil samples for $U C S$}

A specially designed compaction mold was used for sample preparation. PC and MPC stabilized clay specimens were compacted at Optimum Moisture Content (OMC) of high plasticity clayey soil. The mold is characterized by $50.0 \mathrm{~mm}$ in diameter and $100.50 \mathrm{~mm}$ in height to fit the requirement of UCS specimens with a height-to-diameter ratio of 2.01. It was made of stainless steel and longitudinally split into two equal parts. First, the inner surface of the mold was slightly lubricated with silicone grease to minimize the sample disturbance by removing. Next, the mold was assembled, and the soil sample was placed into the mold in three equal layers. Each layer was compacted to a height of $33.5 \mathrm{~mm}$ with a stainless steel tamper of $49.50 \mathrm{~mm}$ in diameter to achieve the desired maximum dry unit weight before placing the next layer. After placing the final layer, the top and bottom end-rings of the compaction mold were disassembled. Finally, the two longitudinal split parts were separated from one another, and the sample was gently taken out. The cement-stabilized soil samples prepared as mentioned above were stored in two different curing conditions.

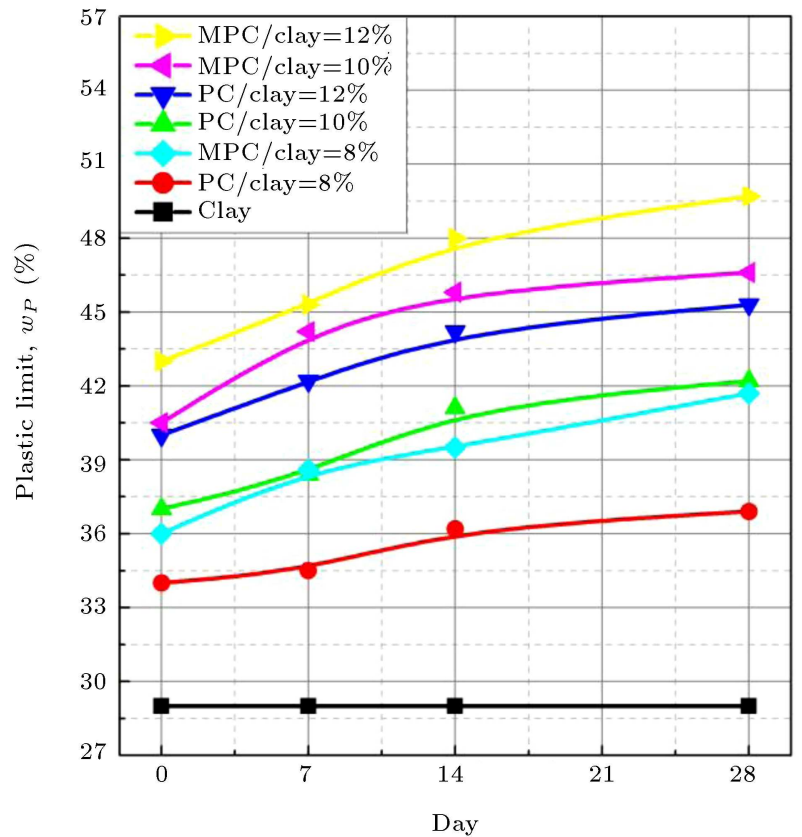

Figure 2. Variations of LL and PL of PC and MPC modified clayey soil samples with time. 

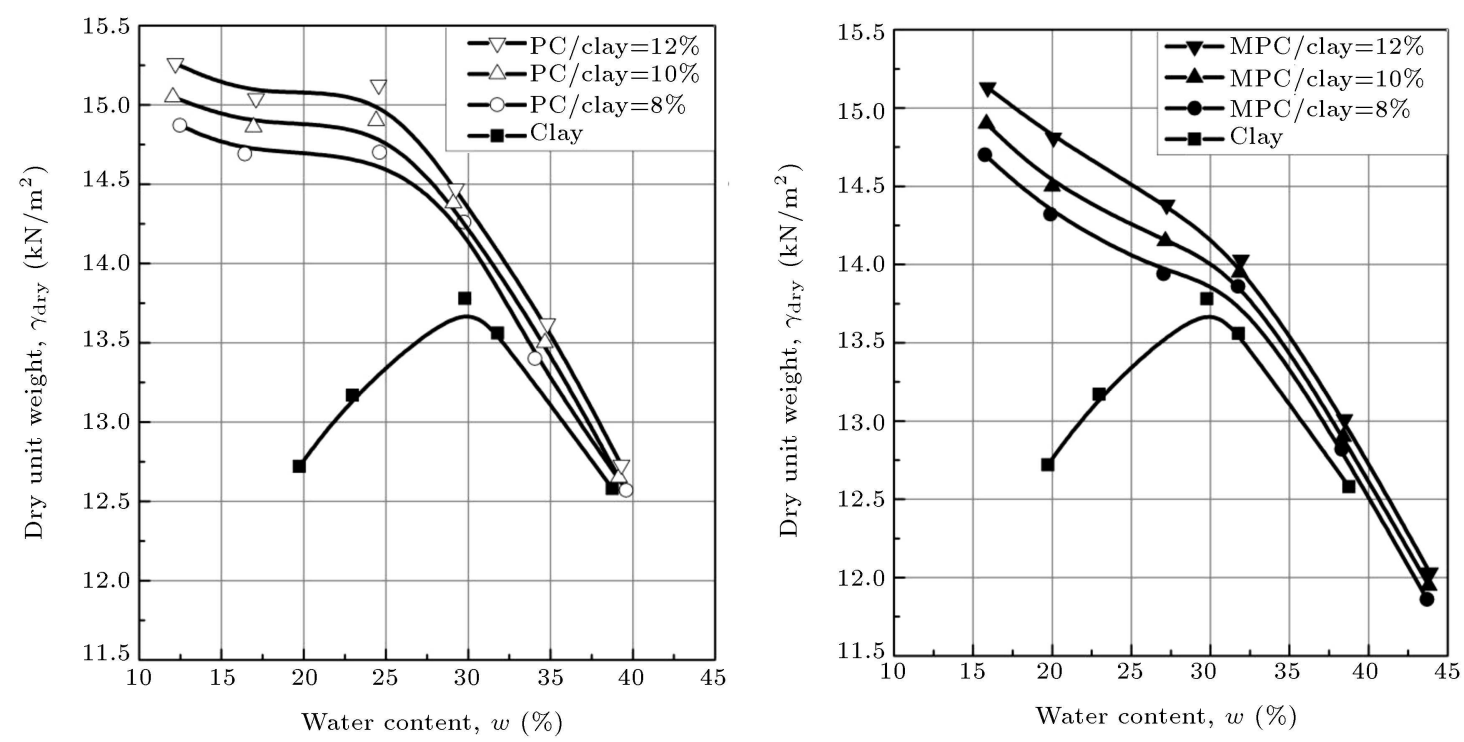

Figure 3. Standard Proctor compaction curves of PC and MPC stabilized clayey soil samples.

Some of them were enclosed in resealable plastic bags to prevent moisture loss and preserved in an $80 \%$ relative humidity room at a temperature of $20^{\circ} \mathrm{C}$. The rest was exposed to air at ambient laboratory temperatures that ranged from $20^{\circ} \mathrm{C}$ to $25^{\circ} \mathrm{C}$ until the day of testing. The stabilized clayey soil samples cured in the humid room and in an open air were referred to as wet and dry samples respectively in the following text.

UCS tests with reference to ASTM D 2166-00 were conducted on both wet and dry PC and MPC stabilized samples at different time intervals of $1,3,7$, $14,28,56$, and 112 days [35]. The related results are displayed in Figure 4. Variations of moisture contents of PC and MPC stabilized clayey soil with time are given in Figure 5.

\subsection{Permeability test}

The permeabilities of PC and MPC treated clayey soil specimens compacted at OMC of untreated clayey soil using standard Proctor test were also investigated by performing falling head permeability tests on the 28th, 56th, 96th, 150th curing days under the hydraulic gradient of 20 in accordance with ASTM D 548403 [36]. Standard Proctor molds $\left(9.44 \times 10^{-4} \mathrm{~m}^{3}\right)$ were used as the permeability cells, and permeability tests were performed at ambient laboratory temperatures that ranged from $20^{\circ} \mathrm{C}$ to $25^{\circ} \mathrm{C}$. The permeant fluid
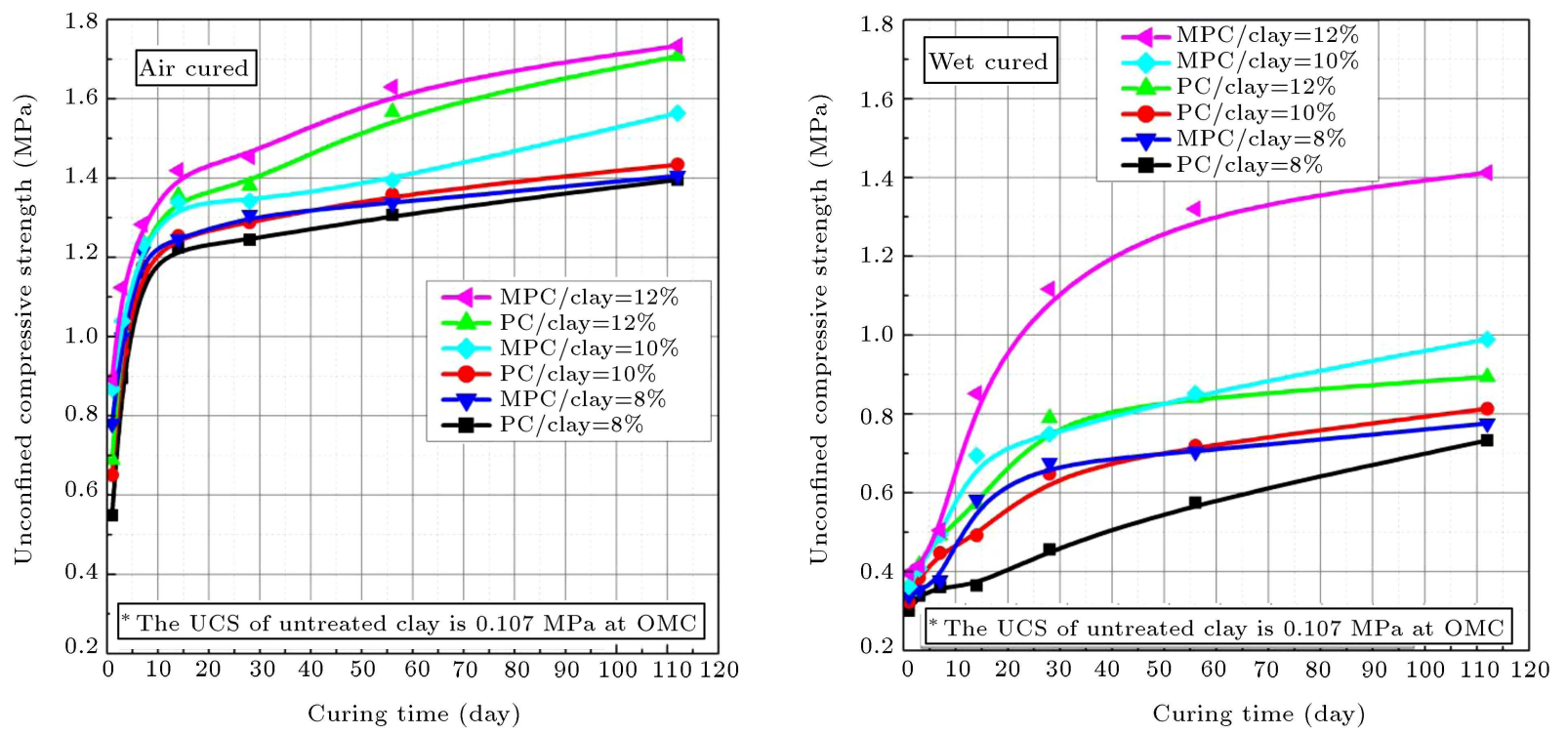

Figure 4. Variation of UCS of PC and MPC stabilized clayey soil samples with time. 

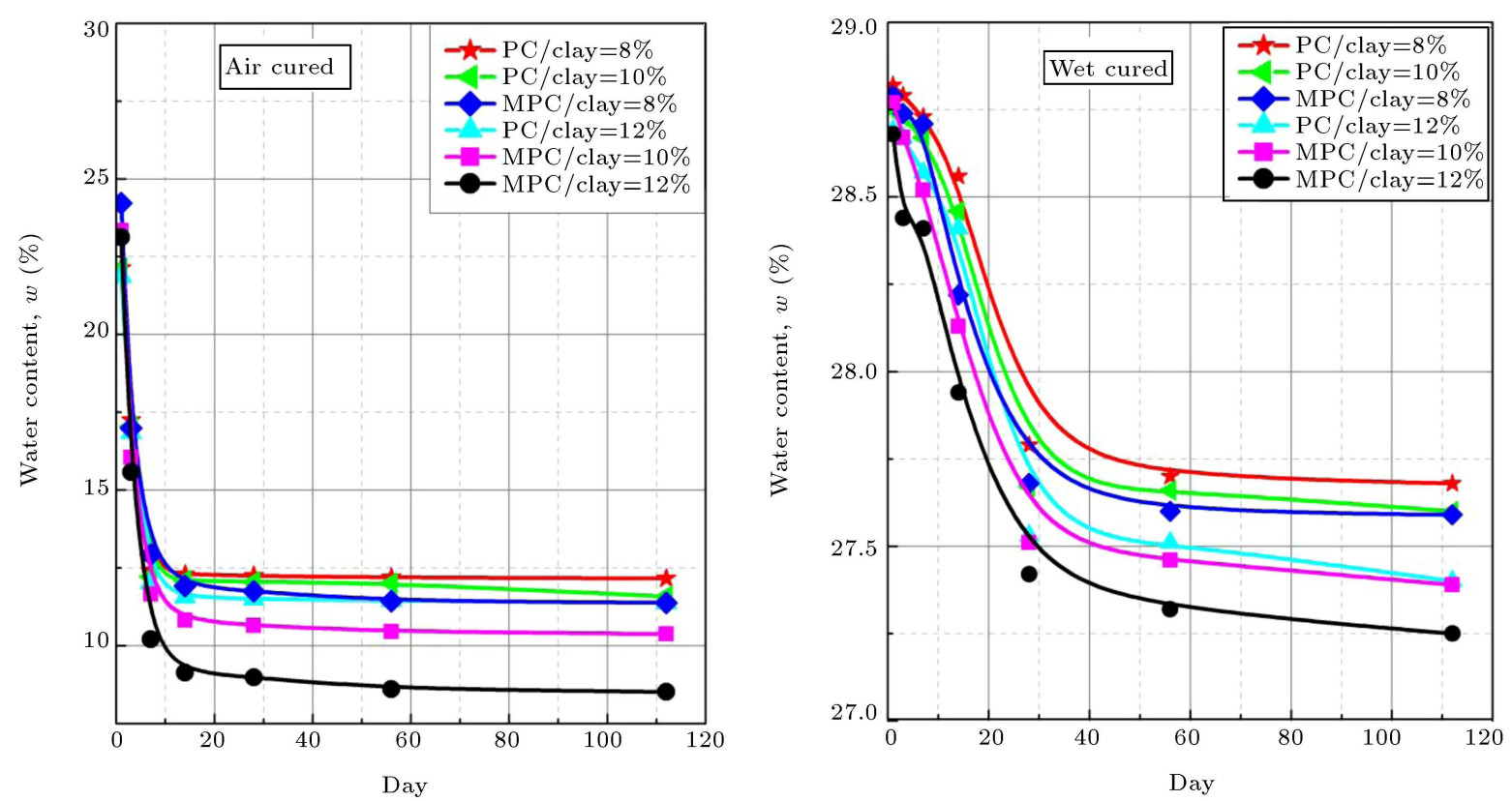

Figure 5. Variation of moisture contents of PC and MPC stabilized clayey soil samples with time.

used for all of the permeability tests was drinkable tap water. The permeability test results of each curing time are shown in Figure 6.

\subsection{Swell potential}

The swell potential of untreated clayey soil sample and the samples treated with different percentages of PC and MPC was measured by conducting swell-consolidation tests with reference to ASTM D 4546 [37]. Consolidometer rings were used to extract samples from the compacted soil in Proctor molds. Before pushing the rings into the compacted soils, the inside of the rings was lubricated with silicone grease to minimize side friction between the rings and soil specimens, thus avoiding sample disturbance. Both ends of the specimens in rings were trimmed level and placed in resealable plastic bags. They were preserved in a room with $80 \%$ humidity at a temperature of $20^{\circ} \mathrm{C}$ for 28 days and, then, subjected to swell tests. Table 3 shows the swelling potentials of PC and MPC stabilized clayey soil specimens.

Table 3. Swelling potentials of stabilized soil samples.

\begin{tabular}{cc}
\hline Properties & Swelling potential (\%) \\
\hline Clay & 9.82 \\
$\mathrm{PC} /$ clay $=8 \%$ & 0.35 \\
$\mathrm{PC} /$ clay $=10 \%$ & 0.25 \\
$\mathrm{PC} /$ clay $=12 \%$ & 0.15 \\
$\mathrm{MPC} /$ clay $=8 \%$ & 0.30 \\
$\mathrm{MPC} /$ clay $=10 \%$ & 0.15 \\
$\mathrm{MPC} /$ clay $=12 \%$ & 0.10 \\
\hline
\end{tabular}

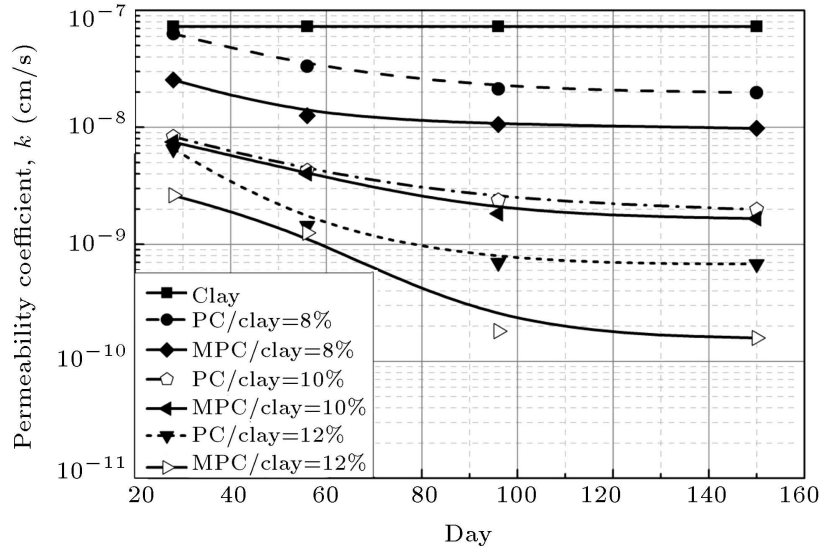

Figure 6. Permeability coefficient variation of $\mathrm{PC}$ and MPC stabilized clay sample with time.

\subsection{Compressibility}

The specimens required for compressibility tests were prepared in the same way as those of the swell tests mentioned above. They were enclosed in resealable plastic bags and cured for 28 days in a room with relative humidity of $80 \%$ at a temperature of $20^{\circ} \mathrm{C}$; then, the compressibility tests were run on the specimens according to ASTM D4546 standard [37]. The related test results are given in Figure 7.

\section{Results and discussion}

\subsection{Consistency limits}

The results of liquid and plastic limits of clayey soil specimens stabilized with different types and percentages of cement are shown in Figure 2. Figure 2 shows 

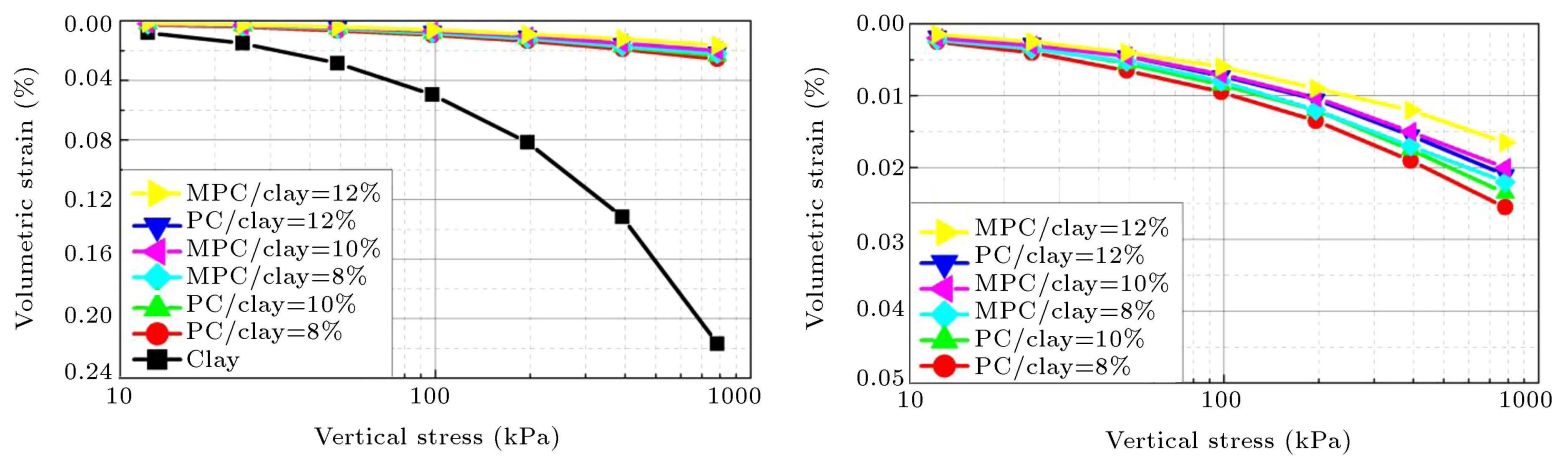

Figure 7. Compressibility behavior of PC and MPC stabilized clayey soil samples.

that liquid limit decreased and plastic limit increased due to the cement addition, in general. Consistency limits change due to the cation exchange reaction and flocculation-aggregation of soil particles. In soils with high plasticity, the encapsulation of clay clusters by deposited cementitious products has the dominant effect, leading to the lowering of liquid limit [38]. An increase in plastic limit results from aggregation and cementation of particles into larger size clusters. Another possible reason is the water trapped within intra-aggregate pores. The presence of intra-aggregate water increases apparent water content without really affecting the interaction between aggregates [39]. As the percentage of cement increased, the liquid limit decreased, and the plastic limit increased. Similar findings were also reported [40]. In addition, liquid limit decreased and plastic limit increased with time. Decreases in liquid limits of PC and MPC stabilized clayey soil for 7,14 , and 28 days of curing period were $39 \% \& 41 \%, 43 \% \& 41 \%$, and $42 \% \& 44 \%$, respectively. In addition, increases in plastic limits of PC and MPC stabilized clayey soil for 7,14 , and 28 days of curing period were $32 \% \& 40 \%, 43 \% \& 47 \%$, and $53 \% \& 59 \%$, respectively.

A decrease in cement particle size further decreased the liquid limit and increased the plastic limit, which occurred due to the fact that as the cement particle size decreased, its specific surface area increased, thus increasing more water consumption.

\subsection{Compaction characteristics}

The OMC of untreated clayey soil was taken as a reference for the addition of cement to clayey soil specimens; then, the compaction process was carried out accordingly. The compaction curves of untreated clayey soil, PC, and MPC stabilized ones are shown in Figure 3. Based on the figure, the compaction curves of PC and MPC stabilized clayey soils were relatively flat and/or almost linear on the dry side of the OMC of untreated clayey soil, respectively. Figure 1 shows that the particles of clayey soil are smaller than those of both PC and MPC. Therefore, clayey soil particles filled the voids formed by the coarser particles of cement. Since the water available in the mixture was insufficient for the hydration of cement, PC and MPC amended clayey soil specimens resisted the compaction effort at low water contents. This behavior was pronounced by MPC modified clayey soil since it had finer particles than those of PC. As the water content increased, the hydration of cement took place and the particles were lubricated, which caused them to slip over each other into a densely packed position. In addition, the maximum dry unit weights of PC and MPC stabilized clayey soils increased at the same compaction energy and at the same water content, because the specific gravities of PC and MPC were greater than those of untreated clayey soil.

Generally, as the cement content increased, the dry unit weight also increased regardless of the cement types, PC or MPC, used (Figure 3 ). Some researchers reported similar findings $[28,40,41]$. Additionally, the water content of soil increased with an increase in cement content. The greater fines, the more surface area; thus, a high amount of water was required to apply good lubrication. In addition, the dry unit weight of the cement-stabilized clayey soil decreased with a decrease in cement particle size. MPC resulted in more flocculation and agglomeration of clayey soil due to the increased surface area. This phenomenon formed more irregular pores, as observed in Figure 8, leading to a corresponding drop in dry unit weight.

\subsection{UCS strength}

Figure 4 displays that UCS values of cement-stabilized clayey soil specimens increase with the increase of PC and MPC contents and curing time both under wet and dry curing conditions. Strength increase with an increase in cement content is attributed mainly to the cement hydration that leads to the dissociation of calcium ions, eventually reacting with soil silica and soil alumina and leading to the formation of pozzolanic products. These pozzolanic products bind together the clay particles or clusters of clay particles or clay minerals and create a new bonded, stronger matrix of soil. Furthermore, since the process of cement hydration and the consequent pozzolanic reaction can 


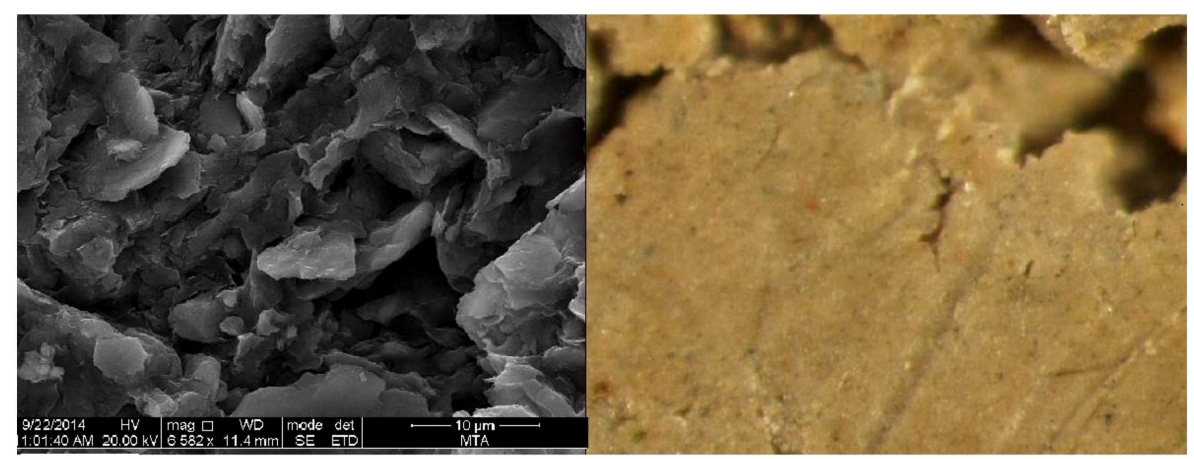

(a) Clay

(b) Clay

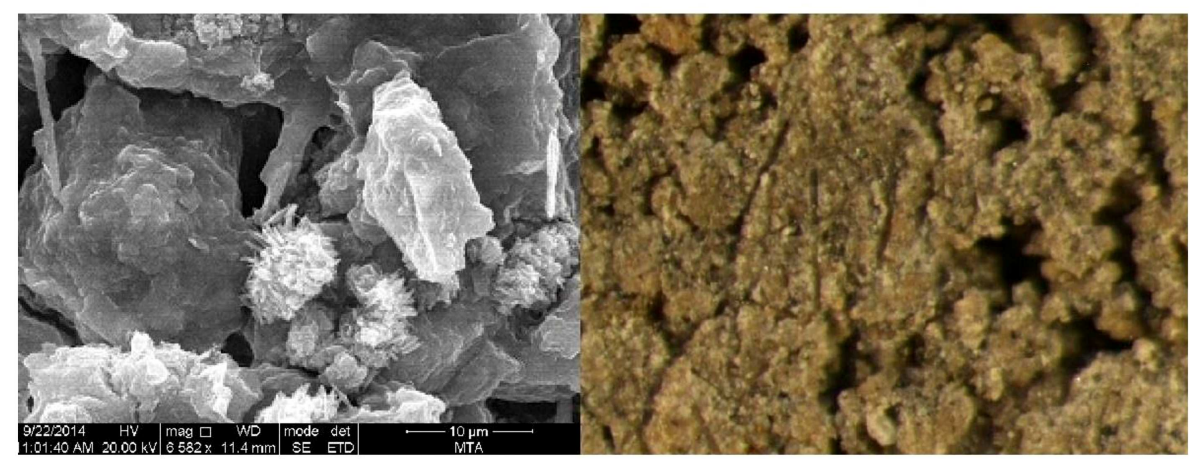

(c) $\mathrm{PC} /$ clay $=8 \%$

(d) $\mathrm{PC} /$ clay $=8 \%$

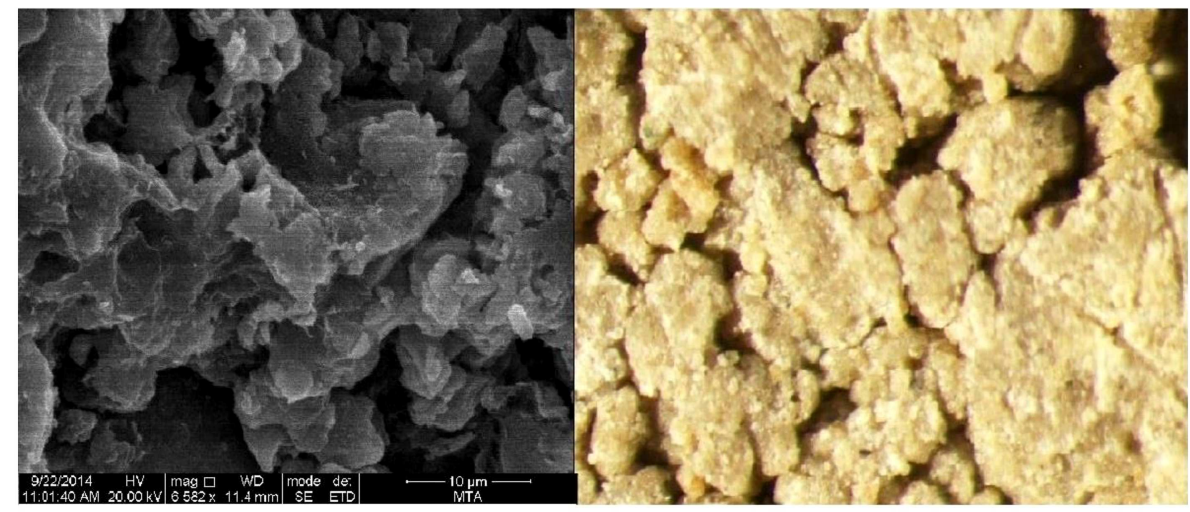

(e) $\mathrm{MPC} / \mathrm{clay}=8 \%$

(f) $\mathrm{MPC} / \mathrm{clay}=8 \%$

Figure 8. SEM and Olympus research stereomicroscope SZX16 photos of PC and MPC stabilized clayey soil samples.

last for months, or even for years, after the mixing, enough water is provided; therefore, the strength of treated soil is expected to increase with time [42]. Several researchers reported that strength increased as cement content and curing time increased [43-48].

The dry and wet strengths of PC stabilized specimens at $8 \%, 10 \%$, and $12 \%$ contents were 1.40 , 1.43 , and $1.71 \mathrm{MPa}$ as well as $0.73,0.81$, and $0.89 \mathrm{MPa}$ at the end of the 112th day, respectively. The dry UCS values of PC stabilized specimens were about 1.86 times those of wet UCS values of PC stabilized specimens. This was due to the effect of the specimen's drying, which caused further moisture content loss of PC stabilized specimens (Figure 5), thus inducing more matric suction pressure. This, in turn, resulted in a further increase in the strength of the cementstabilized clayey soil. According to the figure, while the reduction of the moisture contents of PC stabilized clayey soil specimens was about $47 \%$ under the airdried condition, it was around $4 \%$ under a wet-cured condition at the end of the 112th day. Similarly, since the reduction of the moisture contents of MPC stabilized clayey soil specimens was about $57 \%$ under the air-dried condition, it was around 5\% under a wet-cured condition at the end of the 112th day. An increase in cement fineness caused an increase in specific surface area and, thus, a further reduction in the moisture content of cement stabilized clayey soil. As a result, more strength gain was obtained since the matric suction pressure increased due to 
an increase in the particle fineness of the cementstabilized clayey soil mass. Matric suction was not measured in this experimental study, because the effect of chemical reactions on the cement-stabilized clayey soil was the primary concern. However, moisture content measurements of the cement-stabilized clayey soil specimens with time appeared to reflect the matric suction effect indirectly. At the end of the 112th day, the PC stabilized dry specimens gained 87 and $93 \%$ of their maximum strength within the 28th and 56th days, respectively. Similarly, PC stabilized wet samples gained 77 and $87 \%$ of their maximum strength within the 28th and 56th days, respectively (Figure 4).

On the other hand, the dry and wet strengths of MPC stabilized specimens at $8 \%, 10 \%$, and $12 \%$ contents were $1.41,1.56$, and $1.73 \mathrm{MPa}$ and $0.78,0.99$, and $1.41 \mathrm{MPa}$ at the end of the 112 th day, respectively. At the end of the 112 th day, MPC stabilized dry samples gained 88 and $93 \%$ of their maximum strength on the 28th and 56th days, respectively. The MPC stabilized wet samples gained 81 and $90 \%$ of their maximum strength on the 28th and 56th days, respectively (Figure 4). The dry UCS values of MPC stabilized specimens were about 1.48 times those of wet UCS values of MPC stabilized specimens. Moreover, the rate of the strength increase of wet and dry samples was high up to the 28th day, but decreased sharply afterward. Since the increasing rates of strength between the 56 and 112 days of curing period were 13 and $7 \%$ for the wet-cured and air-dried conditions, respectively, the curing period ended on the 112th day.

It was seen that as the particle size of cement became finer, UCS of cement stabilized clayey soil became higher. In general, the UCS of unstabilized clayey soil was increased about 14 times by PC stabilization and about 15 times by MPC stabilization at the end of 112th day in a dry condition. Similarly, the UCS of clayey soil was increased about 8 times by PC stabilization and about 10 times by MPC stabilization at the end of 112 th day under a wet condition. An increase in fineness led to the production of finer hydration products, filling the voids between coarse particles and making the cementing gel and mixture denser. In this way, the porosity was lowered and pore structure modified; hence, the mechanical strength of the cement-stabilized clayey soil improved.

\subsection{Permeability}

The permeability coefficient of the unstabilized clayey soil compacted at OMC was about $7.03 \times 10^{-8} \mathrm{~cm} / \mathrm{s}$ (Figure 6). While the permeability coefficient of PC stabilized clayey soil was determined between $6.31 \times$ $10^{-8}$ to $6.75 \times 10^{-10} \mathrm{~cm} / \mathrm{s}$, it ranged from $2.53 \times 10^{-8}$ to $1.58 \times 10^{-10} \mathrm{~cm} / \mathrm{s}$ for MPC stabilized clayey soil (Figure 6). Both PC and MPC stabilizations decreased the permeability coefficient of the clayey soil. In addition, the permeability values of $\mathrm{PC}$ and $\mathrm{MPC}$ stabilized clayey soil samples decreased with time and became almost stable after 90 days of wet curing time, and the tests ended thereafter. The secondary cementitious products (calcium silicate hydrate and calcium aluminum silicate hydrate) appear to be deposited on or near the surfaces of the clay clusters. This gives rise to a reduction in entrance pore diameter, yet an increase in particle size. This, in turn, leads to a reduction in permeability over time [24].

Furthermore, the permeability values of the MPC stabilized clayey soil were lower than those of PC stabilized clayey soil. The reason for this was that an increase in cement fineness led to the production of more fine particles, making the cementing gel and mixture denser. In this way, the porosity was lowered, and the permeability was further reduced.

As PC and MPC contents increased, the permeability values of the cement-stabilized clay specimens decreased. An increase in both time and cement content contributed to the production of more cementitious materials and cementing bonds within the soil body, reducing the permeability of the cementstabilized clayey soil.

\subsection{Swell potential}

The swell percentage of the untreated clayey soil cured in sealable plastic bags for 28 days was about 9.82 percent (Table 3).

Both PC and MPC stabilizations reduced the swell potential of the clayey soil significantly. Cation exchange between monovalent cations, such as sodium and potassium, commonly found in expansive clays with higher valence calcium cations due to cement hydration can reduce the attraction of water molecules and, therefore, reduce the swelling potential.

While the swell percentage of PC stabilized clayey soil ranged from $0.35 \%$ to $0.25 \%$, the swell percentage of MPC stabilized clayey soil was between $0.30 \%$ and $0.10 \%$. The swell potential of the cement-stabilized clayey soil was more than $95 \%$ at the end of 28 days of curing period; thus, further measurement with time was not performed.

The swell potential of clayey soil was further reduced by an increase in cement content as well as in the fineness of cement particle size. An increase in the specific surface area of cement consumes more water molecules and, thus, decreases the double layer, resulting in a decrease in repulsion.

\subsection{Compressibility}

The compressibility of the clayey soil compacted at OMC was about $21.7 \%$ (Figure 7 ). Both PC and MPC stabilizations reduced the compressibility of the clayey soil significantly. As pozzolanic reaction occurs, cementitious products gradually infill the intracluster voids 
and strengthen the contacts between soil particles, thereby rendering the soil less compressible. As the compressibility of PC stabilized clayey soil ranged from $2.7 \%$ to $2.1 \%$, the compressibility of MPC stabilized clayey soil was between $2.2 \%$ and $1.6 \%$. Generally, the compressibility of the clayey soil was reduced ten times by both PC and MPC cement stabilizations. The compressibility of the cement-stabilized clayey soil was higher than $90 \%$ at the end of 28 days of the curing period; thus, further measurement with time was not considered.

An increase in cement content and a decrease in cement fineness slightly decreased the compressibility of cement stabilized clay specimens. An increase in cement fineness led to the production of more fine particles, making the cementing gel and mixture denser, stronger, and less prone to compression.

\subsection{Microstructural analysis}

The microstructure of the cement-stabilized clayey soil samples was observed both by SEM and optical microscopy. The techniques were performed after deriving thin slices from the specimens of UCS test. Figure 8(a) and (b) show SEM and Olympus Research Stereomicroscope SZX16 photos of the clay sample compacted at OMC. According to Figure 8(a) and (b), the compacted clay sample exhibited a fairly open type of microstructure with the platy clay particles assembled in a dispersed arrangement.

Figure 8(c) and (f) show micrographs of the cement-treated clay specimens and the formation of flocculation for $8 \% \mathrm{PC}$ and MPC treated clay specimens after 28 days of curing time. The flocculated nature of the fabric became more evident with soil particle clusters interspersed by large openings. At the same time, the flatness of the fabric became less evident, and the degree of reticulation and the formation of ettringite appeared to increase.

The development of floccule aggregates seemed to contribute significantly to the reduction of the swell percent and the increase of strength. The fabric consisted of unevenly distributed pore spaces that might enhance the above-mentioned properties and led to an irregular distribution of water molecules within the specimen volume, and water could not penetrate into the soil volume easily. As a result, the swelling potential and permeability reduced, as already observed. A similar finding was also reported [46].

\section{Conclusions}

The main conclusions drawn from this study are as follows:

- An increase in cement fineness further decreased the liquid limit and increased the plastic limit of the cement-stabilized high plasticity clayey soil. In addition, the liquid limit decreased and the plastic limit increased with time;

- As the cement content increased, the dry unit weight of the cement-stabilized high plasticity clayey soil increased regardless of cement particle size. However, the dry unit weight of the cement-stabilized high plasticity clayey soil decreased with a decrease in cement particle size;

- Dry UCS of MPC stabilized high plasticity clayey soil was nearly the same as that of PC stabilized high plasticity clayey soil. Nevertheless, the wet UCS values of MPC stabilized high plasticity clayey soil were about 1.30 times those of the wet UCS values of PC stabilized high plasticity clayey soil. It was observed that the fineness of cement particle was significantly effective in increasing the UCS of the cement-stabilized high plasticity clayey soil under a wet condition;

- Both PC and MPC stabilizations decreased the permeability of high plasticity clayey soil. Furthermore, the permeability values of PC stabilized high plasticity clayey soil were slightly higher than those of MPC stabilized high plasticity clayey soil. As the cement content in PC and MPC increased, the permeability values of the cement-stabilized high plasticity clayey soil decreased;

- PC and MPC stabilizations reduced the swell potential of high plasticity clayey soil significantly. In addition, the swell potential of the high plasticity clayey soil was further reduced with an increase in the contents of PC and MPC as well as in the fineness of cement particle size;

- The compressibility of the high plasticity clayey soil was reduced ten times by both PC and MPC stabilizations. An increase in cement content and a decrease in cement particle size slightly decreased the compressibility of the cement-stabilized high plasticity clayey soil;

- In general, MPC stabilization of clayey soil was more effective than that of PC.

\section{References}

1. Nelson, J.D. and Miller, R.D., Expansive Soils: Problems and Practice in Foundation and Pavement Engineering, 4th Edn., pp. 20-250, John Wiley and Sons, NewYork, USA (1992).

2. Gourly, C.S., Newill, D., and Schreiner, H.D. "Expansive soils: TRL's research strategy", 1st International Symposium on Engineering Characteristics of Arid Soils, Balkema, London, pp. 247-260 (1994).

3. Yoobanpot, N., Jamsawang, P., and Horpibulsuk, S. "Strength behavior and microstructural characteristics of soft clay stabilized with cement kiln dust and fly 
ash residue", Applied Clay Science, 141, pp. 146-156 (2017).

4. Xiao, H., Wang, W., and Goh, S.H. "Effectiveness study for fly ash cement improved marine clay", Construction and Building Materials, 157, pp. 10531064 (2017).

5. Cong, M., Longzhu, C., and Bing, C. "Analysis of strength development in soft clay stabilized with cement-based stabilizer", Construction and Building Materials, 71, pp. 354-362 (2014).

6. Jahandari, S., Li, S., Saberian, M., and Shahsavarigoughari, M. "Experimental study of the effects of geogrids on elasticity modulus, brittleness, strength, and stress-strain behavior of lime stabilized kaolinitic clay", GeoResJ, 13, pp. 49-58 (2017).

7. Prusinski, J.R. and Bhattacharja, S. "Effectiveness of Portland cement and lime in stabilizing clay soils", Transport. Res. Rec., 1652, pp. 215-227 (1999).

8. Bergado, D.T., Anderson, L.R., Miura, N., and Balasubramaniam, A.S., Soft Ground Improvement in Lowland and Other Environments, 1st Edn., pp. 30427, ASCE Press, New York, USA (1996).

9. Kawasaki, T., Niina, A., Saitoh, S., Suzuki, Y., and Honjo, Y. "Deep mixing method using cement hardening agent", 10th International Conference on Soil Mechanics and Foundation Engineering, 1, Stockholm, Sweden, pp. 721-724 (1981).

10. Porbaha, A., Shibuya, S., and Kishida, T. "State of the art in deep mixing technology", Ground Improvement, 4(3), pp. 91-110 (2000).

11. Cokca, E. "Use of class C fly ashes for the stabilizationof an expansive soil", Journal of Geotechnical and Geoenvironmental Engineering, 127(7), pp. 568-573 (2001).

12. Chew, S.H., Lee, F.H., and Lee, Y. "Jet grouting in Singapore marine clay", 3rd Asian Young Geotechnology Engineering Conf., 1, Singapore, pp. 231-238 (1997).

13. Uddin, K., Balasubramaniam, A.S., and Bergado, D.T. "Engineering behavior of cement-treated Bangkok soft clay", Geotech. Eng. J., 28(1), pp. 89-119 (1997).

14. Lasisi, F. and Ogunjide, A.M. "Effect of grain size on the strength characteristics of cement stabilized lateritic soils", Building and Environment, 19(1), pp. 49-54 (1984).

15. Petry, T.M. and Kelly, S. "Effects of pulverization on the strength and durability of highly active clay soils stabilized with lime and Portland cement", Transportation Research Board, 1sth Edn., pp. 5-66, U.S. (1988).

16. Nagaraj, T.S., Miura, N., Yamadera, A., and Yaligar, P. "Strength assessment of cement admixtures soft clays-Parametric study", International Conference on Ground Improvement Techniques, 1, Macau, China, pp. 379-386 (1997).
17. Saitoh, S. "Experimental study of engineering properties of cement improved ground by the deep mixing method", Ph.D. Thesis, Nibon University (1988).

18. Ahnberg, H., Johansson, S.E., Pihl, H., and Carlsson, T. "Stabilising effects of different binders in some Swedish soils", Ground Improvement, 7(1), pp. 9-23 (2003).

19. Mitchell, J.K. "Soil improvement state of the art report", 10th Int. Conf. on Soil Mechanics and Foundation Engineering, 1, Stockholm, Sweden, pp. 509565 (1981).

20. Tremblay, H., Leroueil, S., and Locat, J. "Mechanical improvement and vertical yield stress prediction of clayey soils from eastern Canada treated with lime or cement", Can. Geotech. J., 38(3), pp. 567-579 (2001).

21. Sarkar, G., Islam, M.R., Alamgir, M., and Rokonuzzaman, M. "Study on the geotechnical properties of cement-based composite fine-grained soil", International Journal of Advanced Structures and Geotechnical Engineering, 1(2), pp. 42-49 (2012).

22. Bell, F.G., Engineering Treatment of Soils, 1sth Edn., pp. 30-300, Chapman \& Hall, London, UK (1993).

23. Sivapullaiah, P.V., Sridharan, A., and Bhaskar, R.K.V. "Role of amount and type of clay in the lime stabilization of soil", Ground Improvement, 4(1), pp. 37-45 (2000).

24. Chew, S.H., Kamruzzaman, A.H.M., and Lee, F.H. "Physicochemical and engineering behavior of cement treated clays", J. Geotech. Geoenviron. Eng., 130(7), pp. 696-706 (2004).

25. Balasubramaniam, A.S., Kamruzzaman, A.H.M., Uddin, K., Lin, D.G., Phienwij, N., and Bergado, D.T. "Chemical stabilization of Bangkok clay with cement, lime and fly ash additives", 13th Southeast Asian Geotechnical Conf., 1, Taipei, Taiwan, pp. 253-258 (1998).

26. Miura, N., Horpibulsuk, S., and Nagaraj, T.S. "Engineering behavior of cement stabilized clay at high water content", Soils and Found., 41(5), pp. 33-45 (2001).

27. Kaushinger, J.L., Perry, E.B., and Hankour, R. "Jet grouting: State of the practice", Proc., Conf. Geotechnical Engineering, Div., Grouting, Soil Improvement and Geosynthetics ASCE, 1, New York, USA, pp. 169181 (1992).

28. Aniculăesi, M., Stanciu, A., and Lungu, I. "Behavior of expansive soils treated with eco-cement", Bulletin of the Polytechnic Institute of Iasi-Construction \& A LVII (LXI), 2, pp. 9-19 (2011).

29. ASTM D422-63, Standard Test Method for ParticleSize Analysis of Soils, ASTM International", West Conshohocken, PA (2002).

30. ASTM D4318-10e1, Standard Test Methods for Liquid Limit, Plastic Limit, and Plasticity Index of Soils, ASTM International, West Conshohocken, PA (2010). 
31. ASTM D854-02, Standard Test Method for Specific Gravity of Soil Solids by Water Pycnometer, ASTM International, West Conshohocken, PA (2002).

32. ASTM D2487-02, Standard Practice for Classification of Soils for Engineering Purposes (Unified Soil Classification System), ASTM International, West Conshohocken, PA (2002).

33. ASTM C150-17, Standard Specification for Portland Cement, ASTM International, West Conshohocken, PA (2017).

34. ASTM D698-00a, Standard Test Methods for Laboratory Compaction Characteristics of Soil Using Standard Effort (12,400 ft-lbf/ $\left.\mathrm{ft}^{3}\left(600 \mathrm{kN}-\mathrm{m} / \mathrm{m}^{3}\right)\right)$, ASTM International, West Conshohocken, PA (2000).

35. ASTM D2166-00, Standard Test Method for Unconfined Compressive Strength of Cohesive Soil, ASTM International, West Conshohocken, PA (2000).

36. ASTM D5484-03, Measurement of Hydraulic Conductivity of Saturated Porous Materials Using a Flexible Wall Permeameter, ASTM International, West Conshohocken, PA (2003).

37. ASTM D4546-08, Standard Test Methods for OneDimensional Swell or Collapse of Soils, ASTM International, West Conshohocken, PA (2008).

38. Brandl, H. "Alteration of soil parameters by stabilization with lime", 10th International Conference on Soil Mechanics and Foundation Engineering, 1, Stockholm, Sweden, pp. 587-594 (1981).

39. Locat, J., Trembley, H., and Leroueil, S. "Mechanical and hydraulic behaviour of a soft inorganic clay treated with lime", Canadian Geotechnical Journal, 33(4), pp. 654-669 (1996).

40. Horpibulsuk, S., Rachan, R., Chinkulkijniwat, A., Raksachon, Y., and Suddeepong, A. "Analysis of strength development in cement-stabilized silty clay from microstructural considerations", Construction and Build Materials, 24(10), pp. 2011-2021 (2010).

41. Richardson, D.N. "AASHTO layer coefficients for cement-stabilized soil bases", Journal of Materials in Civil Engineering, 8(2), pp. 83-87 (1994).

42. Lorenzo, G.A. and Bergado, D.T. "Fundamental characteristics of cement admixed clay in deep mixing", Journal of Materials in Civil Engineering, 18(2), pp. 161-174 (2006).
43. Hago, A.W., Al-Rawas, A.A., and Al-Riyami, A. "Effect of varying cement content and curing conditions on the properties of sarooj (artificial pozzolana)", Building and Environment, 37, pp. 45-53 (2002).

44. Bahar. R., Benazzoug, M., and Kenai, S. "Performance of compacted cement-stabilised soil", Cement \& Concrete Composites, 26(7), pp. 811-820 (2004).

45. Horpibulsuk, S., Suddeepong, A., Chinkulkijniwat, A., and Liu, M.D. "Strength and compressibility of lightweight cemented clays", A pplied Clay Science, $\mathbf{6 9}$, pp. 11-21 (2012).

46. Saride, S., Puppala, A.J., and Chikyala, S.R. "Swellshrink and strength behaviors of lime and cement stabilized expansive organic clays", Applied Clay Science, 85, pp. 39-45 (2013).

47. Kalantari, B. and Prasad, A. "A study of the effect of various curing techniques on the strength of stabilized peat", Transportation Geotechnics, 1(3), pp. 119-128 (2014).

48. Cong, M., Longzhu, C., and Bing, C. "Analysis of strength development in soft clay stabilized with cement-based stabilizer", Construction and Building Materials, 71, pp. 354-362 (2014).

\section{Biographies}

Murat Mollamahmutoglu is a Professor at the Department of Civil Engineering, Gazi University (Ankara, Turkey). He received his BS from Gazi University, MSc from Middle East Technical University (Ankara, Turkey), and PhD from Bradford University (UK). He is a member of Geo-Institute of ASCE and ISSMGE. His research interests include ground improvement, geotechnical earthquake, and geoenvironmental engineering.

Eyubhan Avci is an Associate Professor at the Department of Civil Engineering, Bursa Technical University (Bursa, Turkey). He received his BS from Dokuz Eylül University (İzmir, Turkey) and, then, obtained MSc and PhD from Gazi University (Ankara, Turkey). He is a member of Geo-Institute of ASCE and ISSMGE. His research interests include ground improvement, slope stability, and foundation engineering 